\title{
Seismicity in Idaho and Montana Triggered by the Denali Fault Earthquake: A Window into the Geologic Context for Seismic Triggering
}

\author{
by Allen L. Husker and Emily E. Brodsky
}

\begin{abstract}
We present a case study of dynamically triggered seismicity in Idaho and western Montana from the $2002 M_{\mathrm{W}} 7.9$ Denali fault earthquake to investigate the relationship between measured geological discriminants and propensity for triggering. We first establish triggering. We find events that are not reported in the Advanced National Seismic System catalog in Idaho and Yellowstone following the Denali fault earthquake by filtering broadband waveforms. An $M_{\mathrm{L}} 4.6$ earthquake is discovered near New Meadows, Idaho, during the passage of the Rayleigh waves and another earthquake probably located near Yellowstone. We find that central western Idaho and Yellowstone have statistically significant seismicity increases by applying a $\beta$ test to the cataloged events in the $48 \mathrm{hr}$ after the Denali fault earthquake in Idaho and surrounding regions. We also find that Pine, Idaho, may have triggered events, but the measurement is not robust because of uncertainty in the background seismicity rate. Both central western Idaho and Yellowstone triggered previously during the 1992 Landers earthquake. We then try to determine the local geological conditions necessary for triggered seismicity to occur. Geothermal regions with high total dissolved solids and background seismicity appear to be favorable conditions to trigger earthquakes in the study.
\end{abstract}

\section{Introduction}

Earthquakes were seismically triggered throughout the western United States by the 3 November $2002 M_{\mathrm{W}} 7.9$ Denali fault earthquake (Prejean et al., 2004). Localized regions experienced triggering, but adjacent regions with similar levels of shaking did not. The goal of this study is to distinguish the geophysical characteristics of those regions that trigger from those that do not trigger.

To isolate the possible geophysical factors, we chose an area with pockets of triggering that had uniform shaking and a uniform stress regime. Across Idaho and western Montana, shaking varied by $<15 \%$ during the Denali fault earthquake (Table 1). The region makes up the northern end of the Basin and Range extensional tectonic regime (Stickney and Bartholomew, 1987) with the Snake River Plain and Yellowstone cutting through the basin and range structure. The Western Snake River Plain is an extensional rift that activated when the Eastern Snake River Plain was formed by the migrating Yellowstone hotspot (Wood and Clemens, 2002). The Eastern Snake River Plain and Yellowstone continue to be dominated by magmatism and extensional tectonics (Wood and Clemens, 2002). The Basin and Range, Snake River Plain, and Yellowstone make up a variety of background seismicity and geothermal regimes, the two primary geophysical discriminants identified thus far with dy- namic seismic triggering (e.g., Hill et al., 1993; Anderson et al., 1994; Brodsky et al., 2000).

We find in the following that the localized regions that had robust measures of triggering are central western Idaho and Yellowstone, Wyoming. Both also triggered after the $1992 M_{\mathrm{W}} 7.3$ Landers earthquake (Hill et al., 1993). Yellowstone presented strong evidence of triggering after the Denali fault earthquake. There were 250 earthquakes within $24 \mathrm{hr}$ after the Denali fault earthquake, but only one during the $24 \mathrm{hr}$ before (Husen et al., 2004). It is more difficult to establish seismic triggering in central western Idaho. After filtering waveforms from broadband seismic stations in and around Idaho, we found a previously unrecognized $M_{\mathrm{L}} 4.6$ earthquake located $7 \mathrm{~km}$ from New Meadows, Idaho. We spend the first section of this article locating and establishing the magnitude of the uncataloged event, and determining the statistical significance of all events within and surrounding Idaho and western Montana after the Denali fault earthquake. We then examine the geophysical context of those regions and find that geothermal regions with a high amount of total dissolved solids (TDS) and some measurable background seismicity appear to generate conditions favorable to dynamic triggering. 
Table 1

The Maximum Stress from Each Component Measured in MPa

\begin{tabular}{lcccc}
\hline & Bozeman, MT (BOZ) & Hailey, ID (HLID) & Missoula, MT (MSO) & Newport, WA (NEW) \\
\hline Z component & 0.056 & 0.066 & 0.025 clipped* & 0.063 \\
N component & 0.111 clipped & 0.095 clipped & 0.139 & 0.131 \\
E component & 0.110 & 0.120 clipped & 0.109 & 0.140 \\
\hline
\end{tabular}

Clipped values are minimums. The northern Bozeman component and horizontal Hailey components are barely clipped. The stress is measured with the following formula: $\sigma \approx \mu \nu / V_{\mathrm{R}}$, where $\mu$ is shear modulus (assumed to be $30 \mathrm{GPa}$ ), $v$ is particle velocity (measured from seismograms), and $V_{\mathrm{R}}$ is Raleigh wave phase velocity (assumed to be $3.4 \mathrm{~km} / \mathrm{sec}$ ).

*The Missoula $\mathrm{Z}$ component is severely clipped at a low amplitude, suggesting a possible gain problem.

\section{Data Analysis}

Uncatalogued Earthquakes

The waveforms from six broadband seismic stations in the U.S. National Seismic Network (USNSN) and one from the University of Oregon (UO) network (Fig. 1) were bandpass-filtered $(2-19 \mathrm{~Hz})$ to remove the long-period Denali fault earthquake waves and high-frequency noise. A 2$\mathrm{Hz}$ cutoff diminishes the Denali fault earthquake wave train that has traveled more than $2300 \mathrm{~km}$ from the source, while allowing the largest local earthquake in the wave train to be measured without the filter affecting the measurement. We chose a $19-\mathrm{Hz}$ upper cutoff to filter high-frequency noise because 20 samples per second was the Nyquist frequency. Filtering revealed earthquakes that were missing from the Advanced National Seismic System (ANSS) catalog (Fig. 2) because they were obscured by the mainshock. The ANSS catalog has an apparent seismicity gap for roughly $30 \mathrm{~min}$ after the Denali fault earthquake. During this period, there were at least two earthquakes of magnitudes that ordinarily would have been detected: (1) an $M_{\mathrm{L}} 4.6$ located at $45.02^{\circ}$ $\mathrm{N}, 116.33^{\circ} \mathrm{W}$ (approximately $7 \mathrm{~km}$ from New Meadows, Idaho) occurring at 22:27:02; (2) an $M_{\mathrm{L}} 2.6$ located approximately $175 \mathrm{~km}$ from Bozeman, Montana, occurring at 22:30:40.

The former event was visible on at least seven regional broadband stations (Fig. 1). It was located by using a standard 1D velocity model for the region from the Montana Bureau of Mines and Geology (MB) and the Hypoellipse program (Lee and Lahr, 1975). Because the closest station was $220 \mathrm{~km}$ away, we had no control on depth and therefore arbitrarily fixed the depth at $10 \mathrm{~km}$ to locate the earthquake. Hypoellipse errors assuming fixed depths were $<1 \mathrm{~km}$ and do not account for systematic errors due to lateral velocity variations. We also generated synthetic Wood-Anderson records from the filtered broadband records and used the horizontals to determine that the local magnitude $M_{\mathrm{L}}$ is 4.6 . The filtering procedure used here results in an underestimation of the standard network coda magnitude because $1-$ to $5-\mathrm{Hz}$ frequencies are important for identifying the end of the coda for events $>M 3$. We tested the sensitivity of the value of $M_{\mathrm{L}}$ to the filter band and found that the result of $M_{\mathrm{L}} 4.6$ is robust.

The latter event was only visible at BOZ because HLID is clipped or not available and the other stations appear to be too far to measure it. Assuming a uniform velocity model $\left(v_{\mathrm{P}}=6.5 \mathrm{~km} / \mathrm{sec}\right.$ and $\left.v_{\mathrm{S}}=3.76 \mathrm{~km} / \mathrm{sec}\right)$, the observed $P-S$ time requires that the event was $175 \mathrm{~km}$ from the station. Following the same procedure as previously, we find the $M_{\mathrm{L}}$ magnitude is 2.6. Yellowstone is $\sim 110-175 \mathrm{~km}$ from Bozeman and independent evidence shows seismicity at Yellowstone increased by more than a factor of 40 during the $24 \mathrm{hr}$ after the Denali fault earthquake mainshock (Husen et al., 2004). Because the stations on the other side of Bozeman from Yellowstone did not record the earthquake and a large seismicity increase occurred in Yellowstone, it is likely that this earthquake is another Yellowstone event. We mention this earthquake because it is not recorded elsewhere.

\section{Seismic Triggering Analysis}

The probability that observed earthquakes are triggered is evaluated using the $\beta$-statistic developed by Matthews and Reasenberg (1988) for determining quiescence. The $\beta$ statistic measures the difference between the number of events and the expected number normalized by the standard deviation.

$$
\beta \equiv \frac{N(t, \Delta t)-\langle N(t, \Delta t)\rangle}{\sigma(N(t, \Delta t))}
$$

where $N(t, \Delta t)$ is the number of events during the interval between $t-\Delta t$ and $t,\langle N(t, \Delta t)\rangle$ is the expectation value of $N(t, \Delta t)$, and $\sigma(N(t, \Delta t))$ is the variance of $N(t, \Delta t)$. The $\beta$ statistic is then the number of standard deviations by which the seismicity exceeds the background seismicity for the given period. The previous 10 years of the ANSS catalog for earthquakes above the magnitude completeness threshold of $M 2.5$ are used for the background seismicity and to determine the variance and expectation value of $N(t, \Delta t)$. The ANSS catalog is a composite of many different network's catalogs with different magnitude scales that are not necessarily consistent. We confirmed the regional completeness threshold by limiting the dataset to only events with $M_{\mathrm{C}}$ magnitudes. The completeness threshold still held at $M$ 2.5. We also measured $\beta$ using a limited data set of only those earthquakes determined with $M_{\mathrm{C}}$ and found the same regions exhibit high $\beta$. 


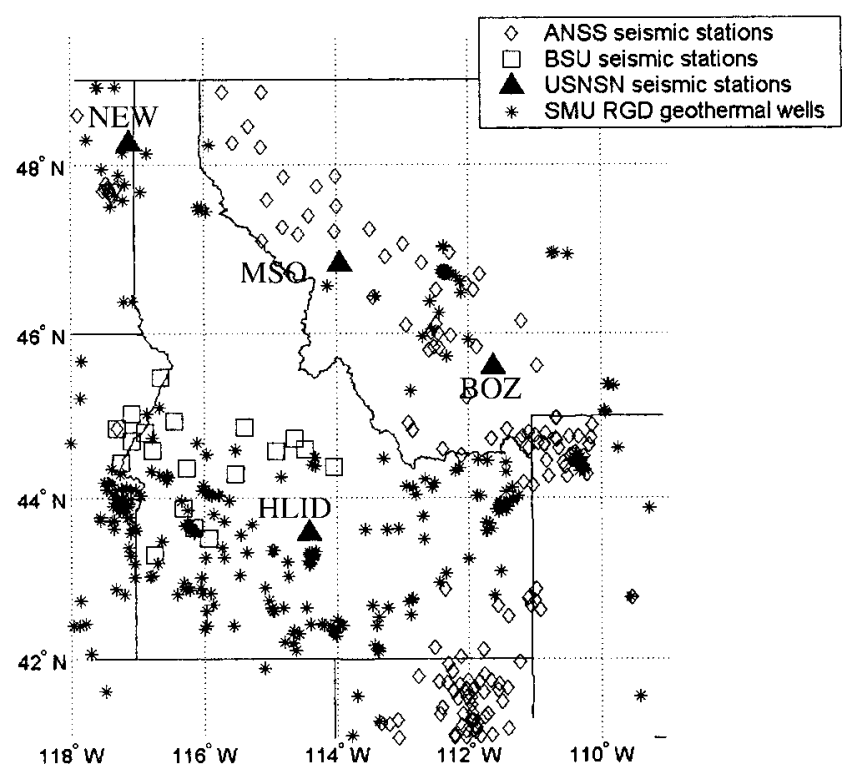

Figure 1. Location of geothermal wells and seismic stations. The broadband stations are used in this study to locate the $M_{\mathrm{L}} 4.6$ near central western Idaho. Additional broadband stations outside the map used to locate the earthquake are HAWA $(46.39,-119.53)$ and WVOR $(42.43,-118.64)$ from the USNSN and PIN (43.81, - 120.87) from the UO network. The broadband stations are all $2500-3100 \mathrm{~km}$ away from the Denali fault.

The choice of $\Delta t$ must balance the trade-off between having too few data, which occurs for a small $\Delta t$, and having too much uncorrelated activity, which occurs for a large $\Delta t$. The sensitivity of the results to the choice of $\Delta t$ is examined by comparing the hourly results for $\Delta t=1 \mathrm{hr}$ through 63 $\mathrm{hr}$. The ANSS did not record earthquakes in the study region until about $30 \mathrm{~min}$ after the passage of the wave train. Central western Idaho and Yellowstone both showed positive $\beta$ values by $2 \mathrm{hr}$ after the Denali fault earthquake. After $63 \mathrm{hr}$, western Montana near Canada starts to show a positive $\beta$ value. We consider this uncorrelated activity as it is not seen initially. We show only $\Delta t=24$ and $48 \mathrm{hr}$ (Table 2) as examples.

We also examine robustness by testing the sensitivity of our result to bin area. The trade-off in area balances between having too few data, which occurs with small bins, and having bins span across different geological zones, making it impossible to associate them with specific regions. We consider results that are consistent for seismicity counted in $10 \times 10 \mathrm{~km}^{2}$ through $110 \times 110 \mathrm{~km}^{2}$ size bins in $10 \times 10$ $\mathrm{km}^{2}$ steps. Areas with fewer than 10 earthquakes recorded during the 10-year period are discarded because of a lack of data. When bins are less than $20 \times 20 \mathrm{~km}^{2}$, only Yellowstone has more than 10 earthquakes $M \geq 2.5$ over 10 years. Bins greater than $100 \times 100 \mathrm{~km}^{2}$ lack resolution but are high in similar regions. Central western Idaho and Yellowstone are in the same bin when bin sizes are around $450 \times$
$450 \mathrm{~km}^{2}$ and greater. Again, we only display two bin sizes (Table 2) as an example.

The $\beta$-statistic (Table 2) measures robust increases in seismicity in central western Idaho and Yellowstone (Fig. 4). For the past 10 years of data, $10 \%$ of the time one or more bins in the study region had $\beta$-statistic values greater than 10 . Four earthquakes $M \geq 2.5$ have occurred in the past 10 years in the $40 \times 40 \mathrm{~km}^{2}$ bin where the $M_{\mathrm{L}} 4.6$ earthquake found in this study occurs. This bin is not included in Figure 4 or Table 2 because of the small background-seismicity rate. Because so few large earthquakes occur in this region, there may be an even greater significance of the earthquake occurring within the Denali fault earthquake wave train. Bins with no earthquakes in the 2-day window all have a negative $\beta$-value near zero, ranging from -0.22 to -0.08 . All the negative $\beta$-bins have decreases less than one standard deviation from the earthquake rate. It is not possible to robustly determine if any region experienced quiescence.

The upper limit of the local static stress change from an earthquake is $\Delta \sigma \leq M_{0} /\left(4 \pi r^{3}\right)$, where $M_{0}$ is the seismic moment and $r$ is the distance from the earthquake. The Denali fault earthquake moment was $7.5 \times 10^{20} \mathrm{~N} \mathrm{~m}$ according to the Harvard Catalog and it was $2350 \mathrm{~km}$ away from the nearest edge of the study region. The local static stress change is less than $5 \mathrm{~Pa}$ and, therefore, is unlikely to have affected the local earthquakes.

Triggering appears as a short, 1- to 3-day effect. The long-term seismicity is dominated by local conditions, not stress loading from the Denali fault earthquake. After 3 days only two bins in Yellowstone exhibit a positive $\beta$-value and both values are less than any bin in the study region during the first $48 \mathrm{hr}$.

The use of limited data requires some qualification of our results. The $\beta$-value in central western Idaho is based on one earthquake that occurred after the Denali fault earthquake and 18 earthquakes from the previous 10 years. The $M_{\mathrm{L}} 4.6$ earthquake is not used in the determination of $\beta$. The Boise State University (BSU) seismic network was not operational in 2002. The 51-earthquake swarm recorded by the BSU seismic network in Cascade after the 1992 Landers earthquake would not have been recorded in 2002 because the largest 1992 earthquake was only an $M_{\mathrm{L}}$ 1.7. Since there are so few earthquakes recorded in central western Idaho, each of the 18 earthquakes during the previous 10 years also represents a statistically significant increase in earthquake rate. The earthquake occurring $1 \frac{1}{2} \mathrm{hr}$ after the Denali fault earthquake is distinct from the other 18 earthquakes because it occurred a short time after a $M>7$ earthquake and close to $M_{\mathrm{L}} 4.6$ found in the wave train of the Denali fault earthquake suggesting a possible swarm of undetected earthquakes, and the previous episode of dynamic triggering that occurred in the region after the Landers earthquake.

There were also two events near Pine, Idaho, that may be triggered events. The Montana Bureau of Mines and Geology (MB) seismic network recorded an $M_{\mathrm{C}} 3.6$ earthquake near Pine $8.5 \mathrm{hr}$ after the passage of the wavetrain (Fig. 3). 


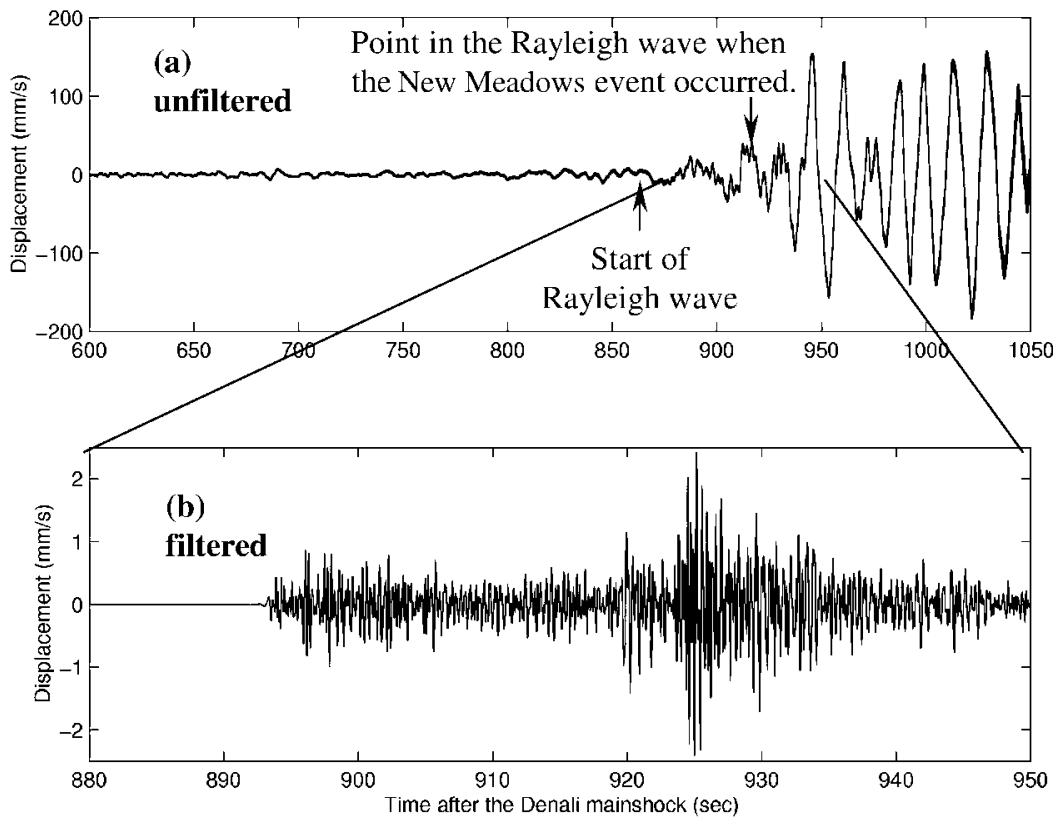

At New Meadows a local event starts after 2 cycles of the Rayleigh wave.

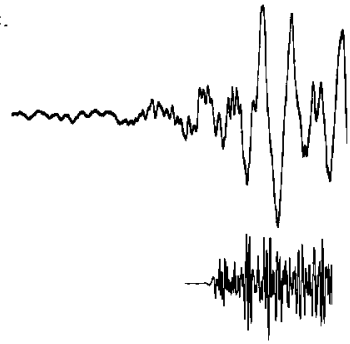

(c)

At Central Western Idaho

Body waves from the local event travel faster than the Rayleigh

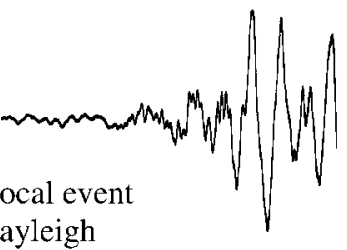

waves, advancing along the phase.

Figure 2. Example of bandpass filtering (2-19 Hz) of HLID waveform. (a) The unfiltered vertical component of the waveform at HLID. (b) A section of the filtered waveform. (c) A schematic representation of the local body wave and surface wave. The length of the arrow represents the wave speed. Because the body waves of the local earthquake travel faster than the Denali fault earthquake surface waves, the body waves arrive at HLID before the section of the surface wave that triggered it. The $M_{\mathrm{L}}$ 4.6 ruptures $861 \mathrm{sec}$ after the Denali fault earthquake or $71 \mathrm{sec}$ after the beginning of the Rayleigh wave, that is, after approximately two cycles of the Rayleigh wave.

Table 2

$\beta$ Statistic Values for Regions with Evidence of Triggering

\begin{tabular}{|c|c|c|c|c|c|c|c|c|c|c|c|c|}
\hline \multirow[b]{2}{*}{ Location } & \multicolumn{4}{|c|}{$\Delta t=2$ days, $40 \times 40 \mathrm{~km}^{2}$} & \multicolumn{4}{|c|}{$\Delta t=2$ days, $80 \times 80 \mathrm{~km}^{2}$} & \multicolumn{4}{|c|}{$\Delta t=1$ day, $40 \times 40 \mathrm{~km}^{2}$} \\
\hline & ${ }^{\circ} \mathrm{N}$ & ${ }^{\circ} \mathrm{W}$ & $\beta$ & $N$ & ${ }^{\circ} \mathrm{N}$ & ${ }^{\circ} \mathrm{W}$ & $\beta$ & $N$ & ${ }^{\circ} \mathrm{N}$ & ${ }^{\circ} \mathrm{W}$ & $\beta$ & $N$ \\
\hline \multirow[t]{7}{*}{ Yellowstone } & 44.06 & 110.76 & 3.9 & 1 & 44.24 & 111.51 & 6.4 & 1 & 44.06 & 110.76 & 4.0 & 1 \\
\hline & 44.42 & 111.22 & 5.2 & 1 & 44.24 & 110.51 & 15.5 & 10 & 44.42 & 111.22 & 5.3 & 1 \\
\hline & 44.42 & 110.72 & 4.5 & 2 & 44.96 & 111.43 & 5.7 & 3 & 44.42 & 110.72 & 4.7 & 2 \\
\hline & 44.42 & 110.22 & 22.0 & 7 & 44.96 & 110.42 & 4.2 & 2 & 44.42 & 110.22 & 18.9 & 6 \\
\hline & 44.78 & 111.18 & 5.9 & 3 & & & & & 44.78 & 111.18 & 6.0 & 3 \\
\hline & 44.78 & 110.67 & 2.2 & 1 & & & & & 44.78 & 110.67 & 2.3 & 1 \\
\hline & 44.78 & 110.17 & 6.1 & 1 & & & & & 44.78 & 110.17 & 6.3 & 1 \\
\hline Central western Idaho & 44.42 & 116.24 & 12.2 & 1 & 44.24 & 116.50 & 12.0 & 1 & 44.42 & 116.24 & 12.3 & 1 \\
\hline
\end{tabular}

The latitudes and longitudes are the centers of the bins. $N$ is the number of events occurring in the period $\Delta t$ after the Denali fault earthquake (equation 1). When $40 \times 40 \mathrm{~km}^{2}$ bins are used the area where the $M_{\mathrm{L}} 4.6$ event occurs has less than 10 earthquakes over 10 years so it is not shown due to a lack of data. 


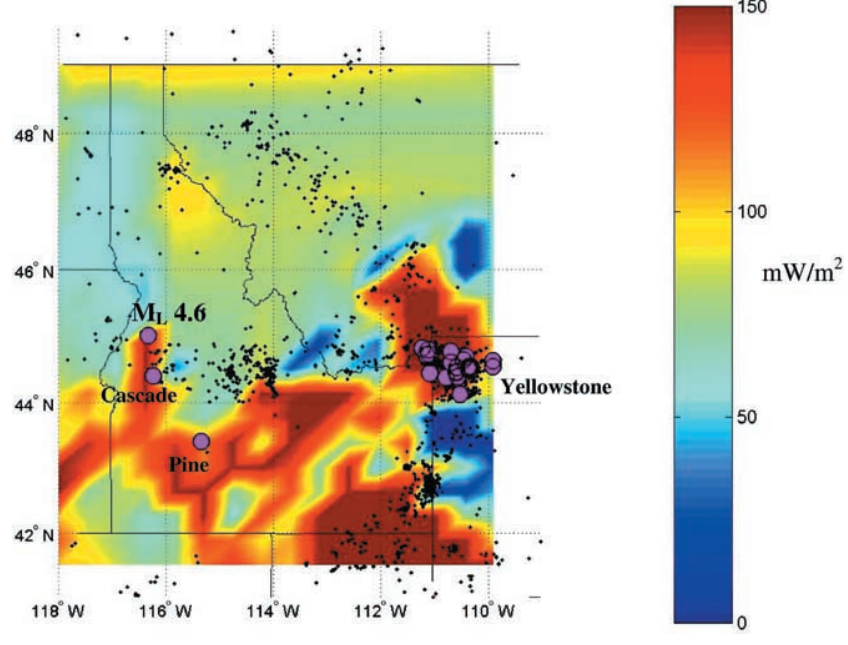

Figure 3. Heat flow, seismicity from September 1991 through December 1999 (black dots), and seismicity in the 2 days after the Denali fault earthquake (purple circles). The scale is truncated to show regional heat flow as individual heat-flow measurements can be $>800 \mathrm{~mW} / \mathrm{m}^{2}$. Heat-flow data selected from the RGD are restricted to sites rated as mediumhigh quality measured in boreholes or in geothermal systems. The most northwesterly purple circle is the $M_{\mathrm{L}} 4.6$ found in the wave train. The black dots represent a combined catalog from the ANSS and the Boise State University (BSU) seismic network. The seismicity following the Denali fault earthquake was only recorded by the ANSS because the BSU seismic network is no longer operational.

Examining this event with a closer station, HLID, we find that it is actually two events. They are an $M_{\mathrm{L}} 3.3$ and an $M_{\mathrm{L}}$ 3.2 , respectively. The second one occurs $68 \mathrm{sec}$ after the first. The $P$ wave of the second earthquake was in the $S$ wave of the first by the time they reached the MB seismic network, making it appear to be one event. We cannot determine whether the two Pine earthquakes are triggered events. In the last 10 years $432 M \geq 2.5$ earthquakes were recorded by the ANSS in Idaho. Only one of those earthquakes was recorded near Pine. This would appear to give much greater significance to the two Pine earthquakes following the Denali fault earthquake. However, there is no evidence of earthquakes occurring in Pine immediately with passage of the Denali fault earthquake wave train. In central western Idaho and Yellowstone, using ANSS-cataloged events alone gives an elevated $\beta$-value when $\Delta t>1 \mathrm{hr}$. If we determine the $\beta$ value in Pine despite the lack of background seismicity, there is no elevated $\beta$-value until $\Delta t>8 \mathrm{hr}$.

\section{Establishing Geological Context for Triggering}

Both central western Idaho and Yellowstone have previously had seismicity triggered by distant earthquakes. The Landers earthquake affected both regions (Hill et al., 1993). The central western Idaho swarm following the Landers earthquake was within $2 \mathrm{~km}$, that is, within location error, of the cataloged central western Idaho earthquake following the Denali fault earthquake. A local array also recorded a swarm near Brownlee, Idaho, immediately following the $1964 M_{\mathrm{W}} 9.2$ Alaska earthquake (J. Zollweg, personal comm.). The Brownlee swarm is $\sim 40 \mathrm{~km}$ southwest of the Denali fault earthquake-triggered $M_{\mathrm{L}}$ 4.6.

The rest of Idaho and western Montana do not have a history of triggering. Although our evaluation of past triggering is undoubtedly biased by station distribution, the Denali fault earthquake did not cause elevated $\beta$-values anywhere else in the region except possibly Pine, Idaho (Fig. $3)$. In this section we attempt to find features that the two triggered regions have in common that separate them from the rest of Idaho and western Montana. The possible distinguishing features are numerous. We focus particularly on heat flow and the presence of hot springs because these have been commonly cited by previous studies as correlated with triggered areas (Hill et al., 1993; Brodsky et al., 2000).

We can find hot springs near all our triggered areas. The hot springs of Yellowstone are world famous. More interestingly, the $M_{\mathrm{L}} 4.6$ New Meadows event is only $3 \mathrm{~km}$ from a commercially developed sulfate-rich hot spring called Zim's Hot Springs. However, hot springs are plentiful throughout Idaho, so the anecdotal evidence is not conclusive. Hot springs are particularly plentiful on the Idaho batholith where fractured rocks provide ready conduits for deep fluids, yet no triggering has been documented past the western rim of the batholith.

Perhaps we must use a more specific definition of a geothermal region to separate triggering and nontriggering areas. We now investigate whether areas with high heat flow are correlated with triggering. We use heat-flow data from the Southern Methodist University (SMU) Regional Geothermal Database (RGD). The RGD is a compilation of heatflow data in wells from more than 500 different references, including studies by academia and industry. The locations of the wells with high-quality heat flow are plotted in Figure 1. A contour map made from the heat-flow data is displayed in Figure 3.

Although all the triggered areas overlie high-heat-flow regions, the map shows many high-heat-flow regions that do not have triggered seismicity. A more restrictive set of discriminants is needed. We add two additional criteria to distinguish the triggering areas. (1) Some background seismicity must be present. It is unlikely that seismicity will be triggered in a hot heat flow, but nearly aseismic region like the Snake River Plain (Fig. 3). (2) The geothermal system must have high total dissolved solids (TDS). This second criterion is incorporated to distinguish the clean, radioactively heated geothermal systems over the Idaho batholith from the deep-seated systems at the edge of the Snake River Plain and overlying the Yellowstone magmatic system.

We combine the three criteria by defining a metric $C$ as

$$
\begin{array}{ll}
C \equiv \frac{H}{\max (H)} \times \frac{T D S}{\max (T D S)}, & \text { if } S>0 \\
C \equiv 0, & \text { if } S=0,
\end{array}
$$

where $H$ is heat flow truncated to $0-150 \mathrm{~mW} / \mathrm{m}^{2}, T D S$ is 
(a)

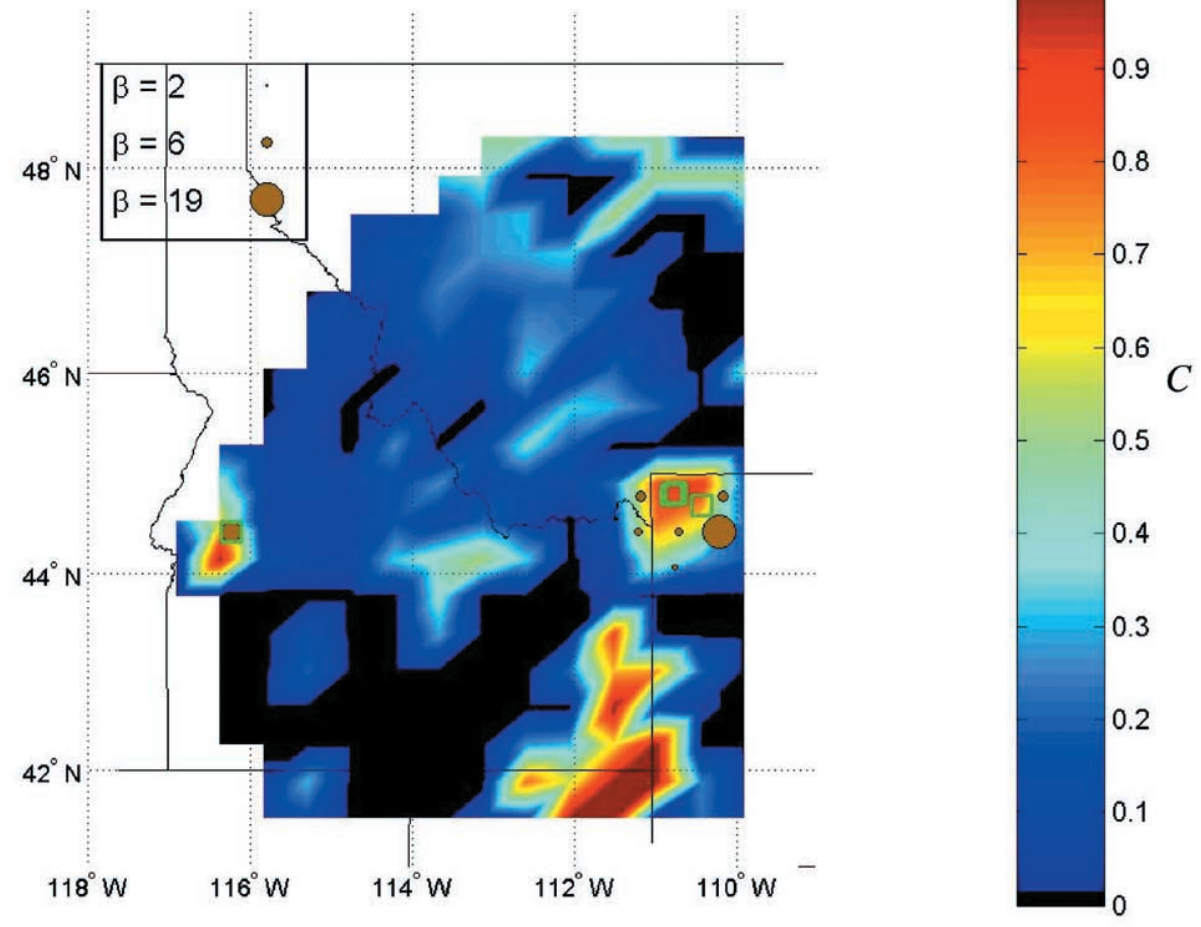

(b)

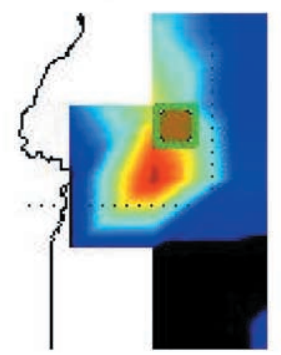

(c)

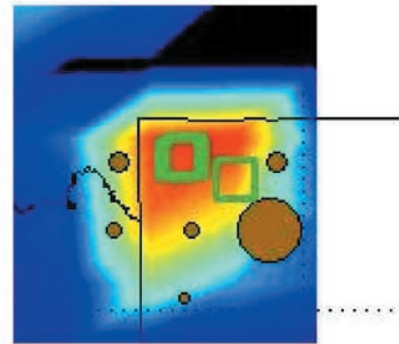

Figure 4. Combined heat flow, TDS, and background seismicity (equation 2) with the $\beta$-statistic (equation 1) and triggered seismicity after the Landers earthquake. (a) Entire study region. (b) Close up of central western Idaho. (c) Close up of Yellowstone. Three regions of high heat flow, high $T D S$, and high background seismicity emerge. (1) central western Idaho, (2) Snake River Plain, and (3) Yellowstone. Region 2 may be an extension of the triggering in northwest Utah (Pankow et al., 2004). The green squares are the location of trigger events following the $1992 M_{\mathrm{W}} 7.3$ Landers earthquake. In Yellowstone, the squares are the events recorded by the ANSS for $24 \mathrm{hr}$ after the Landers earthquake, although 102 earthquakes were attributed to triggering (Hill et al., 1993). In central western Idaho, only 1 of the 51 Landers-triggered earthquakes that triggered was visible on enough seismograms to have its location recorded in the BSU seismic network catalog.

total dissolved solids truncated to $0-1500 \mathrm{ppm}$, and $S$ is the number of earthquakes from 1992 to 2002 in the ANSS catalog per $40 \times 40 \mathrm{~km}$ bin. The TDS data are from the Oregon Institute of Technology's Geo-Heat Center Database (GHCD). The GHCD data include more than 100 references, including many of the same studies used for the heat-flow database. A few sites in Yellowstone reported chemical analyses without $T D S$, so we calculated the TDS from the reported concentrations.
Figure 4 shows $C$ and the $\beta$-statistic. The robustly triggered earthquakes are only in regions of high $C$ values $(>0.6)$. Southeastern Idaho is the only area in the study region that has a high $C$ value but does not have an elevated $\beta$-value. However, the region did have four small earthquakes $\left(M_{\mathrm{L}}<2.5\right)$ within 2 days after the Denali fault earthquake that may be part of the Utah triggered seismicity discussed elsewhere in this volume (Pankow et al., 2004). 


\section{The Question of Triggering at Pine}

Although we do not have enough seismicity in the past 10 years to determine whether the earthquakes at Pine following the Denali fault earthquake represent triggering, they may fit with difficulty into the geological context established for triggering in the previous section. There is high heat flow because it is the edge of the Snake River Plain (Brott et al., 1978; Blackwell et al., 1991). There is evidence of some background seismicity from a large historical earthquake in 1905 in the vicinity according to the Significant U.S. Earthquakes (1568-1989) catalog at the National Earthquake Information Center (NEIC). However, there has never been a local network to measure smaller earthquakes. The lack of station coverage gives us no means of detecting the smaller events, which were critical for evaluating central western Idaho triggering after the Landers earthquake. There is no evidence of high TDS. Therefore, if the events near Pine are indeed triggered, they are consistent with only part of our model.

\section{Summary and Conclusions}

Despite the lack of stations in central Idaho, we have found an $M_{\mathrm{L}} 4.6$ event that occurred at the beginning of the Denali fault earthquake wave train in central western Idaho near the location of Landers-triggered seismicity (Hill et al., 1993). We applied Mathews and Reasenberg's (1988) $\beta$ statistic to find all areas that had elevated regions of seismicity after the Denali fault earthquake in and around Idaho. Yellowstone and central western Idaho were the two regions that had robust signs of triggered seismicity.

We then used normalized heat flow combined with the presence of background seismicity and high TDS as a method for discriminating triggering and nontriggering areas. We conclude that the data are consistent with high heat flow under a seismically active region being a prerequisite for triggering. More speculatively, we add the criterion of a mineral-rich geothermal system to restrict the study area to the regions in Idaho and Montana that robustly triggered. Robust measures of triggering only occur in regions with $C$ $>0.6$.

This study is far from exhaustive. It is possible that other sets of variables can be found to distinguish central western Idaho and Yellowstone from the rest of the region. In particular, the use of TDS is primarily empirical. More research is required to determine the geological conditions that provide a setting favorable for triggering and create high TDS. However, based on our observations in the northern Basin and Range region of Idaho and Montana, we have not yet been able to find any other useful discriminants.

\section{Acknowledgments}

We thank Michael Stickney for providing resources and the Montana velocity model, Jim Zollweg for providing data from the BSU seismic network, and Paul Davis, Stephanie Prejean, Karen Felzer, and Rebecca Har- rington for discussions. We also thank the NEIC and Berkley Data Center hosting the ANSS for catalog data, and the USNSN and UO networks for waveform data. This work was in part supported by National Science Foundation Grant EAR-0238455.

\section{References}

Anderson, J. G., J. N. Brune, J. N. Louie, Y. Zeng, M. Savage, G. Yu, Q. Chen, and D. dePolo (1994). Seismicity in the western Great Basin apparently triggered by the Landers, California, earthquake, 28 June 1992, Bull. Seism. Soc. Am. 84, 863-891.

Blackwell, D. D., J. L. Steele, and L. S. Carter (1991). Heat-flow patterns of the North American continent: a discussion of the Geothermal Map of North America, in Neotectonics of North America, D. B. Slemmons, E. R. Engdahl, and D. D. Blackwell (Editors), Geological Society of America "Decade of North American Geology," 423-436.

Brodsky, E. E., V. Karakostas, and H. Kanamori (2000). A new observation of dynamically triggered regional seismicity: earthquakes in Greece following the August, 1999 Izmit, Turkey earthquake, Geophys. Res. Let. 27, 2741-2744.

Brott, C. A., D. D. Blackwell, and J. C. Mitchell (1978). Tectonic implications of the heat flow of the Western Snake River Plain, Idaho, Geo. Soc. Am. Bull. 89, 1679-1707.

Hill, D. P., P. A. Reasenberg, A. Michael, W. J. Arabaz, G. Beroza, D. Brumbaugh, J. N. Brune, R. Castro, S. Davis, D. dePolo, W. L. Ellsworth, J. Gomberg, S. Harmsen, L. House, S. M. Jackson, M. J. S. Johnston, L. Jones, R. Keller, S. Malone, L. Munguia, S. Nava, J. C. Pechmann, A. Sanford, R. W. Simpson, R. B. Smith, M. Stark, M. Stickney, A. Vidal, S. Walter, V. Wong, and J. Zollweg (1993). Seismicity remotely triggered by the magnitude 7.3 Landers, California, earthquake, Science 260, 1617-1623.

Husen, S., R. Taylor, R. B. Smith, and J. Healser (2004). Impact of the M 7.9 Denali fault earthquake on hydrothermal systems in Yellowstone National Park, Bull. Seism. Soc. Am. 94, no. 6B, S317-S331.

Lee, W. H. K., and J. C. Lahr (1975). HYPO71 (revised); a computer program for determining hypocenter, magnitude, and first motion pattern of local earthquakes, U.S. Geol. Surv. Open-File Rept. 75-0311.

Matthews, M. V., and P. A. Reasenberg (1988). Statistical methods for investigating quiescence and other temporal seismicity patterns, $\mathrm{Pa}$ geoph 126, 357-372.

Pankow, K. L., S. J. Nava, J. C. Pechmann, and W. J. Arabasz (2004) Triggered seismicity in Utah from the 3 November 2002 Denali fault earthquake, Bull. Seism. Soc. Am. 94, no. 6B, S332-S347.

Prejean, S. G., D. P. Hill, E. E. Brodsky, S. E. Hough, M. H. S. Johnston, S. D. Malone, D. H. Oppenheimer, A. M. Pitt, and K. B. RichardsDinger (2004). Remotely triggered seismicity on the United States west coast following the M 7.9 Denali fault earthquake, Bull. Seism. Soc. Am. 94, no. 6B, S348-S359.

Southern Methodist University (SMU) Regional Geothermal Database (RGD), www.smu.edu/geothermal/ (last accessed July 2004).

Stickney, M. C., and M. J. Bartholomew (1987). Seismicity and quaternary faultings of the northern Basin and Range province, Montana and Idaho, Bull. Seism. Soc. Am. 77, 1602-1625.

Wood, S. P., and D. M. Clemens (2002). Geologic and tectonic history of the western Snake River Plain, Idaho and Oregon, in Tectonic and Magmatic Evolution of the Snake River Plain Volcanic Province, Bill Bonnichsen, Craig M. White, and Michael McCurry (Editors), Idaho, Geol. Surv. Bull. 30, 69-103.

Department of Earth and Space Sciences

UCLA

Los Angeles, California 90095-1567

uskerhay@moho.ess.ucla.edu

Manuscript received 13 February 2004. 